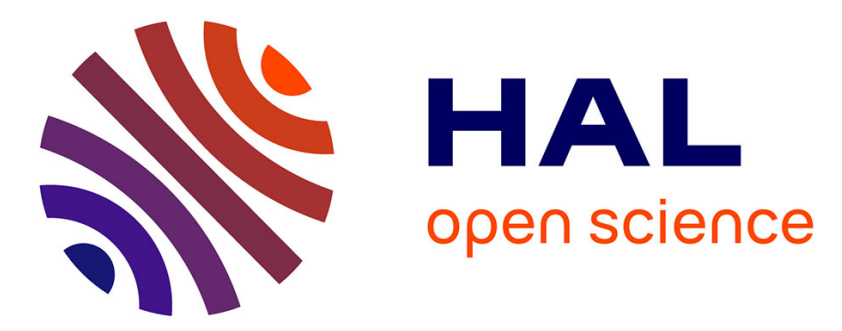

\title{
Surface Damage and Treatment by Impact of a Low Temperature Nitrogen Jet
}

\author{
Hicham Laribou, Claude Fressengeas, Denis Entemeyer, Véronique
}

Jeanclaude, Abdel Tazibt

\section{To cite this version:}

Hicham Laribou, Claude Fressengeas, Denis Entemeyer, Véronique Jeanclaude, Abdel Tazibt. Surface Damage and Treatment by Impact of a Low Temperature Nitrogen Jet. INTERNATIONAL CONFERENCE ON ADVANCES IN MATERIALS AND PROCESSING TECHNOLOGIES (AMPT2010), 2010, Paris, France. pp.1222-1227, 10.1063/1.3552349 hal-02174092

\section{HAL Id: hal-02174092 \\ https://hal.science/hal-02174092}

Submitted on 9 Jul 2019

HAL is a multi-disciplinary open access archive for the deposit and dissemination of scientific research documents, whether they are published or not. The documents may come from teaching and research institutions in France or abroad, or from public or private research centers.
L'archive ouverte pluridisciplinaire HAL, est destinée au dépôt et à la diffusion de documents scientifiques de niveau recherche, publiés ou non, émanant des établissements d'enseignement et de recherche français ou étrangers, des laboratoires publics ou privés. 


\title{
Surface Damage and Treatment by Impact of a Low Temperature Nitrogen Jet
}

\author{
Hicham Laribou ${ }^{1}$, Claude Fressengeas ${ }^{1}$, Denis Entemeyer ${ }^{1}$, Véronique Jeanclaude ${ }^{1}$, \\ Abdel Tazibt ${ }^{2}$
}

${ }^{1}$ LPMM (Laboratoire de Physique et Mécanique des Matériaux) Université Paul Verlaine - Metz / CNRS, Ile du Saulcy, Metz, 57045, France ${ }^{2}$ CRITT TJF\&U; Parc Bradfer, Bar-le-Duc, 55000, France

\begin{abstract}
Nitrogen jets under high pressure and low temperature have been introduced recently. The process consists in projecting onto a surface a low temperature jet obtained from releasing the liquid nitrogen stored in a high pressure tank (e.g. 3000 bars) through a nozzle. It can be used in a range of industrial applications, including surface treatment or material removal through cutting, drilling, striping and cleaning. The process does not generate waste other than the removed matter, and it only releases neutral gas into the atmosphere. This work is aimed at understanding the mechanisms of the interaction between the jet and the material surface. Depending on the impacted material, the thermo-mechanical shock and blast effect induced by the jet can activate a wide range of damage mechanisms, including cleavage, crack nucleation and spalling, as well as void expansion and localized ductile failure. The test parameters (standoff distance, dwell time, operating pressure) play a role in selecting the dominant damage mechanism, but combinations of these various modes are usually present. Surface treatment through phase transformation or grain fragmentation in a layer below the surface can also be obtained by adequate tuning of the process parameters. In the current study, work is undertaken to map the damage mechanisms in metallic materials as well as the influence of the test parameters on damage, along with measurements of the thermo-mechanical conditions (impact force, temperature) in the impacted area.
\end{abstract}

\section{Introduction}

A new method for surface stripping or cleaning has recently been developed by using a nitrogen jet under high containment pressure and low temperature. This process is presented as a friendly and innovative technology compared with other surface treatment processes (chemical stripping, shot peening, water jet...). By analogy and in a first approach, it may be tempting to extrapolate to the case of the nitrogen jet the surface damage mechanisms due to water jets under high pressure or cryogenic carbonic gas jets. However, the thermo-mechanical conditions in the impact area: pressure, temperature, jet velocity, jet composition, are very different. The interaction jet/matter involves a large number of parameters, such as intrinsic jet parameters related to its physical nature (morphology, phase composition, and temperature), parameters of jet formation (tank pressure, nozzle geometry, flow velocity...), test parameters (standoff distance, dwell time...) and parameters of the target (surface hardness, thermo-mechanical properties ...). These various elements combine to produce a large variety of material removal and damage mechanisms. In the following, we present measurements of the thermo - mechanical parameters at impact, and observations of the jet interaction mechanisms with a metallic material surface. 


\section{THERMO-MECHANICAL PARAMETERS OF THE NITROGEN JET IN THE IMPACT AREA}

\subsection{Temperature Measurements}

A cast steel plate $\left(200 \times 100 \mathrm{~mm}^{2}\right)$ was used to measure the temperature in the impacted area. The plate was equipped with K-type thermocouples laid out at various depths $(0.5,3,4$ and $5 \mathrm{~mm})$. All recorded values were compatible with the temperature distributions obtained from the diffusion of a constant heat flow from the point of impact. A characteristic example of the temperature records is shown in FIGURE 1.

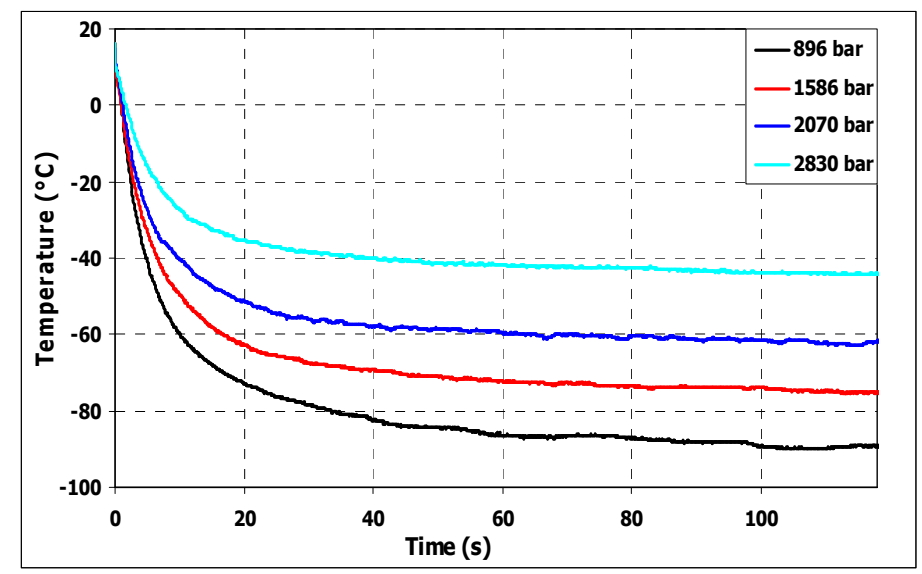

FIGURE 1. Temperature $\left({ }^{\circ} \mathrm{C}\right)$ vs. Time (s) at $0.5 \mathrm{~mm}$ under the impacted surface for various tank pressures

It is seen in the FIGURE 1 that the equilibrium temperature decreases as the operating pressure is increased. The minimum temperature obtained in this configuration is about $-90^{\circ} \mathrm{C}$. It is much higher than the temperature on the outlet side of the exchanger $-150^{\circ} \mathrm{C}$. This increment can be explained by the use of water jet tools (cutting heads), inappropriate in the case of nitrogen jets. The saturated temperature measured by the thermocouple is representative of the jet temperature of the nitrogen jet at impact because the heat capacity of the plate near the thermocouple is low.

\subsection{Measurement of the force impinged on the surface}

Series of measurements were performed, in order to quantify the impact force of the nitrogen jet on the work piece surface. This force was measured by using a calibrated force sensor U93/1kN (weakly sensitive to the temperature, and thermally protected from the jet). Selected results obtained during the tests are presented in FIGURE 2, which shows an example of the evolution of the impact force induced by the jet on the surface for various standoff distances. The maximum recorded impact force is about $10 \mathrm{~N}$ for an operating pressure of 2100 bars. Note that the impact force is independent of the standoff distance, which indicates that the total mass flow rate takes part to the impact. The impact force value $F$ relates to the mass flow rate in Eq. 1:

$$
F=\dot{m} . U, \dot{m}=\rho . S . U
$$

Here $\dot{m}$ is the mass flow rate, $\rho$ the average nitrogen density, $S$ the jet cross-section area and $U$ is the average velocity of the jet. The latter can be estimated from the value of the mass flow rate delivered by the system. For a mass flow rate of $80 \mathrm{~g} / \mathrm{s}$ [1], $U$ turns out to be of the order of 125 $\mathrm{m} / \mathrm{s}$. Since the jet diameter is about $2 \mathrm{~mm}$, Eq. (1) also suggests that the average mass density 
is $\rho \approx 640 \mathrm{~kg} \cdot \mathrm{m}^{-3}$. Hence, the jet may be either biphasic or hypercritical. In addition the dynamic pressure is of the order of $5 \mathrm{MPa}$, while the static pressure is the atmospheric pressure. Due to nitrogen compressibility, interactions with the surrounding medium and overall dissipation, all these values evolve with the distance from the nozzle and a more detailed analysis is needed to account for the jet heterogeneity [2]. However they provide useful indications for the assessment of the interactions of the jet with the targeted material.

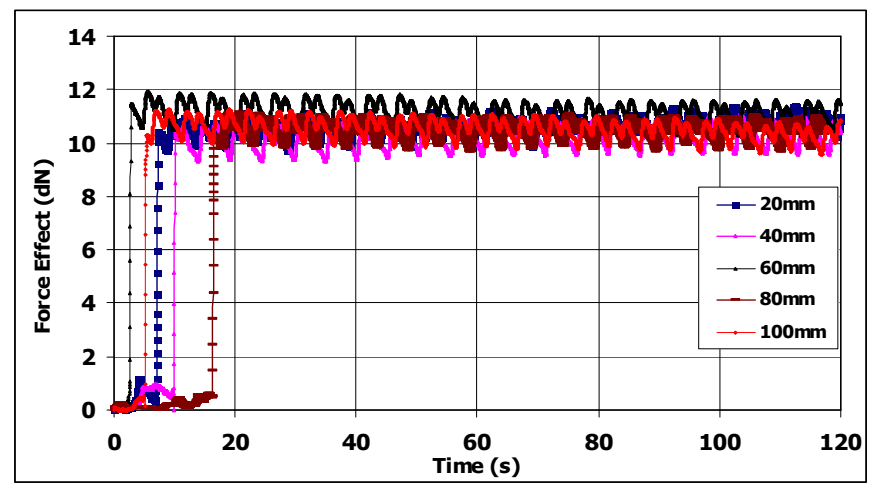

FIGURE 2. Force vs. Time for different standoff distance (mm). Operating pressure is 2100 bars.

\section{THE MECHANISMS OF METALLIC MATERIAL DAMAGE}

This section is devoted to the relations between the mechanical properties of the material and the damage patterns under the impact of the nitrogen jet.

\subsection{Material Composition and Environmental Conditions}

The low carbon mild steel E24 was selected for the tests (C max. 0.06\%, P max. 0.015\%, S max. $0.05 \%$, hardness $150 \mathrm{HV}$, density $7710 \mathrm{~kg} \cdot \mathrm{m}^{-3}$ ). The stress vs. strain curves obtained from tensile tests at low and room temperature are presented in FIGURE 3. Note the dramatic increase in the yield stress and decrease in ductility at low temperature. Series of experimental investigations were carried out using polished samples $\left(35 \times 20 \times 10 \mathrm{~mm}^{3}\right)$ with the standoff distance varying in the range 20 to $100 \mathrm{~mm}$. The rest of testing conditions was: nozzle diameter $0.2 \mathrm{~mm}$, operating pressure 3000 bars, forward speed of the jet $20 \mathrm{~mm} / \mathrm{min}$.

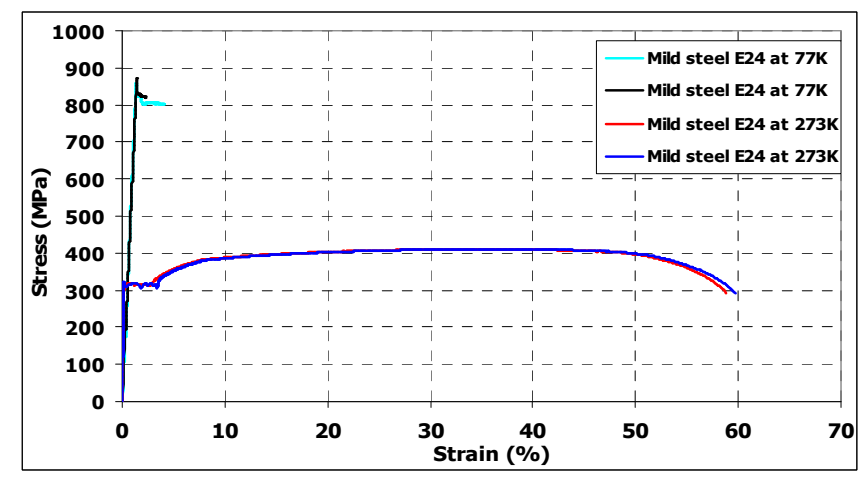

FIGURE 3. Stress vs. strain curves of mild steel E24 at low and room temperatures (2 tests each)

\subsection{Experimental Results and discussion}


Selected results obtained from the tests on mild steel E24 are presented in this section.

\section{a. Fractography of Damage Surface}

The impacted zone on the target and the damage were observed with a Scanning Electron Microscope (SEM). The SEM pictures show the evolution of matter removal with the standoff distance $d_{s}$. For $d_{s}=30$ and $40 \mathrm{~mm}$, a discontinuous and irregular slit is observed along the course of the jet, with a more pronounced removal of matter at the sample edges (FIGURE 4). For $d_{s}=50$ to $100 \mathrm{~mm}$, the jet erases an irregular and continuous groove (FIGURE 5a). Microobservation of the impacted area for these standoff distances reveals two principal damage regions: (a) a strongly affected central area showing fracture by cleavage (FIGURE 5b), (b) two side zones with shallow and isolated damage areas, probably associated with impacts of liquid or dense hypercritical droplets. These areas show various damage features: spalling, micro-cracking (FIGURE 5c), as well as inter-connected networking cracks (FIGURE 5d). Crack nucleation could be due to high gradients of thermal retraction between the surface and the bulk material.
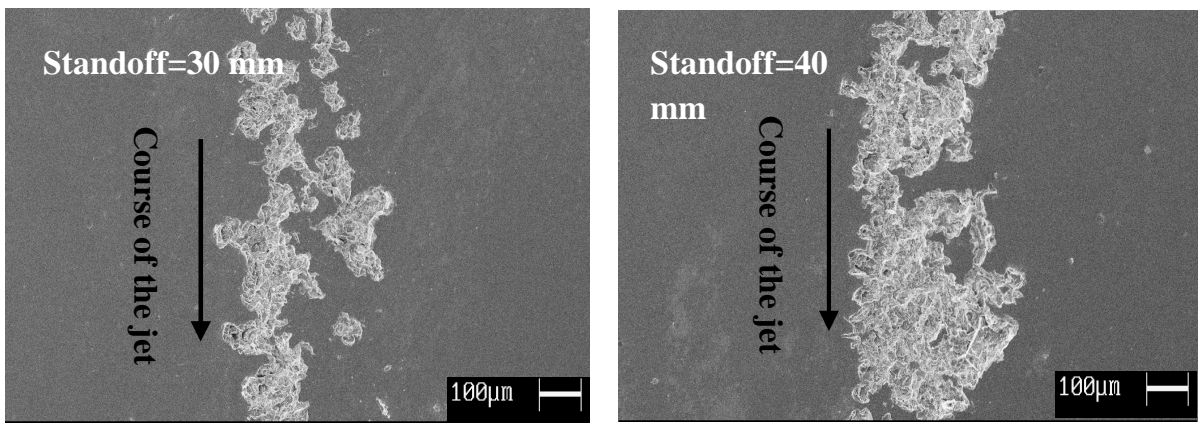

FIGURE 4. Discontinuous slit for standoff distance 30 and 40mm

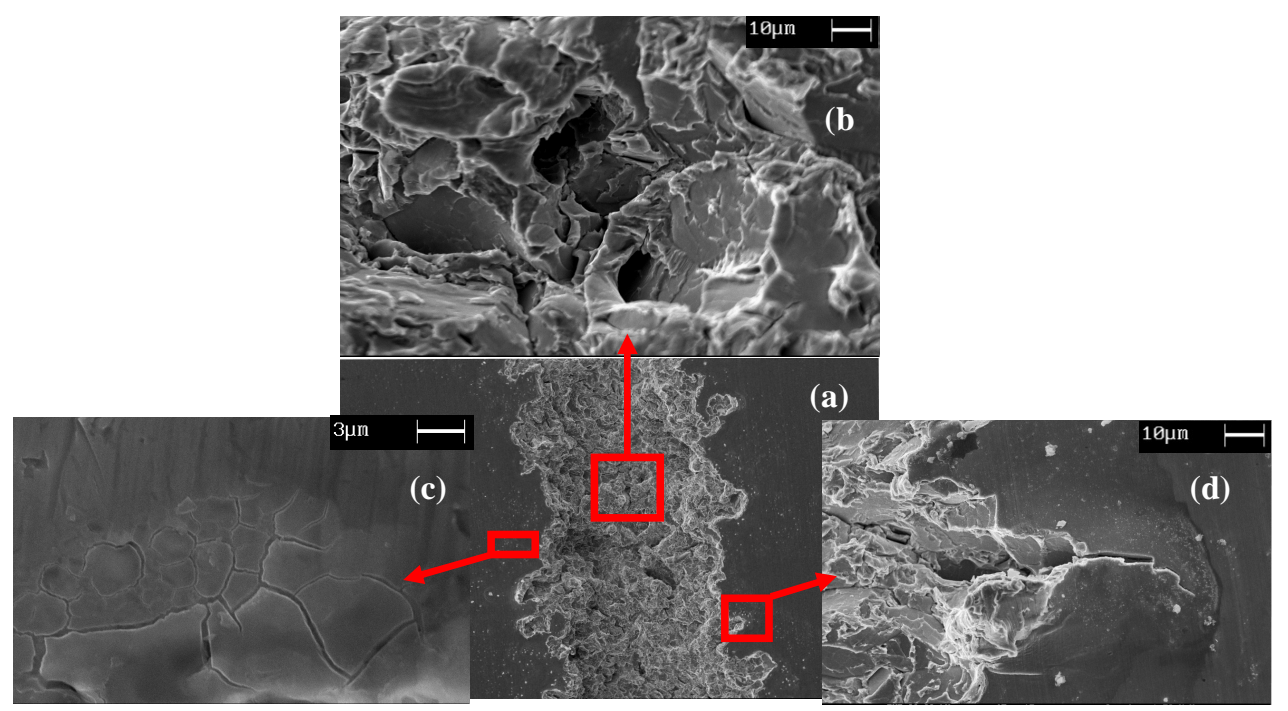

FIGURE 5. Typical damage patterns for standoff distances 50, 60, 70, 80, 90 and 100mm

\section{b. Measurements of the width and depth of surface damage}

Micro-optical measurements of the affected area were carried out on the impacted specimens. The results indicate a significant evolution of these characteristics with the standoff distance. 


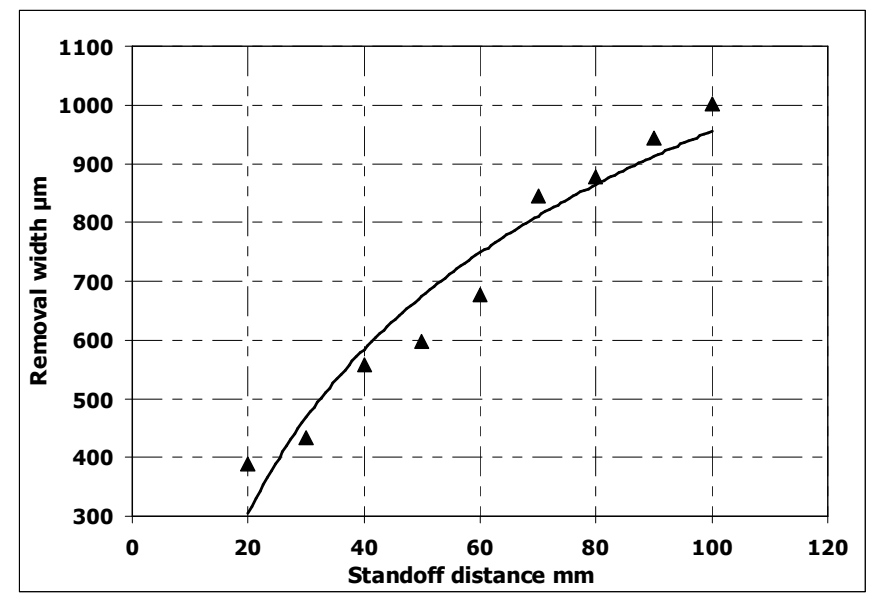

FIGURE 6. Removal width vs. standoff distance

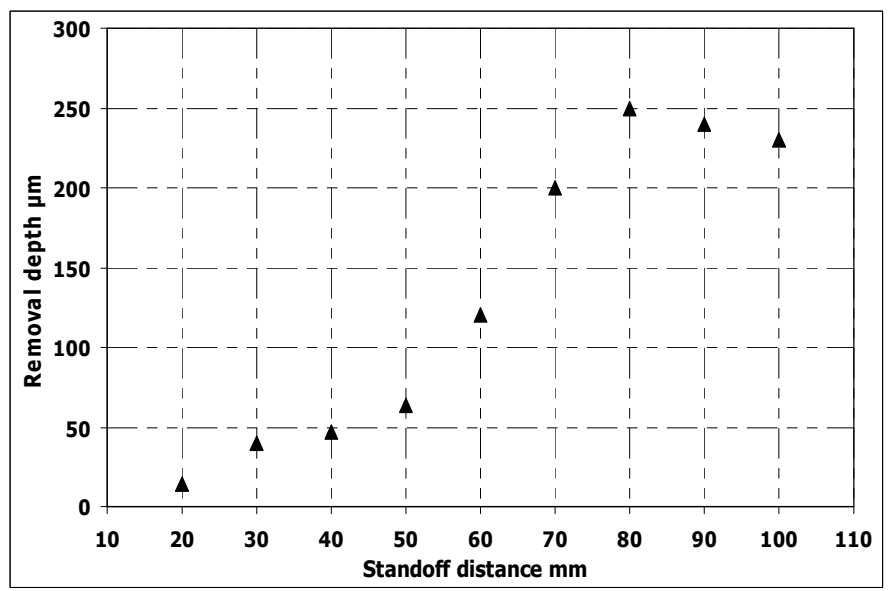

FIGURE 7. Removal depth vs. standoff distance

FIGURES 6 and 7 suggest that the jet starts to have an appreciable effect beyond a certain standoff distance (approximately 50mm), and an optimal range for removal is $60-90 \mathrm{~mm}$. Note that the removal width is about half the jet diameter. The correlation between the standoff distance and surface damage is probably controlled by two factors: (i), the presence of liquid or dense hypercritical nitrogen at the impact and, (ii), the increase in the jet diameter with standoff distance. The former suggests gas condensation as nitrogen flows down the jet, while the latter is due to side interactions of the jet with the ambient atmospheric gas.

\section{c. Hardness measurements using micro-indentation}

Measurements of micro-hardness in the neighborhood of the jet groove are shown in FIGURE 8, by using a ZWICK ZHV1/2 Micro-Vickers. It is seen that, next to the groove, the microhardness increases well above the average value in the absence of jet treatment $(150 \mathrm{HV})$. This average value is recovered 800 to $1000 \mu \mathrm{m}$ away from the groove. The increase in the microhardness could be due to internal stress building, grain fragmentation due to thermal shock and/or ultrafast nitrogen transport and absorption, perhaps due to grain decohesion. These conjectures will be tested using DRX and EBSD measurements as well chemical analysis of the impacted areas in the near future. 


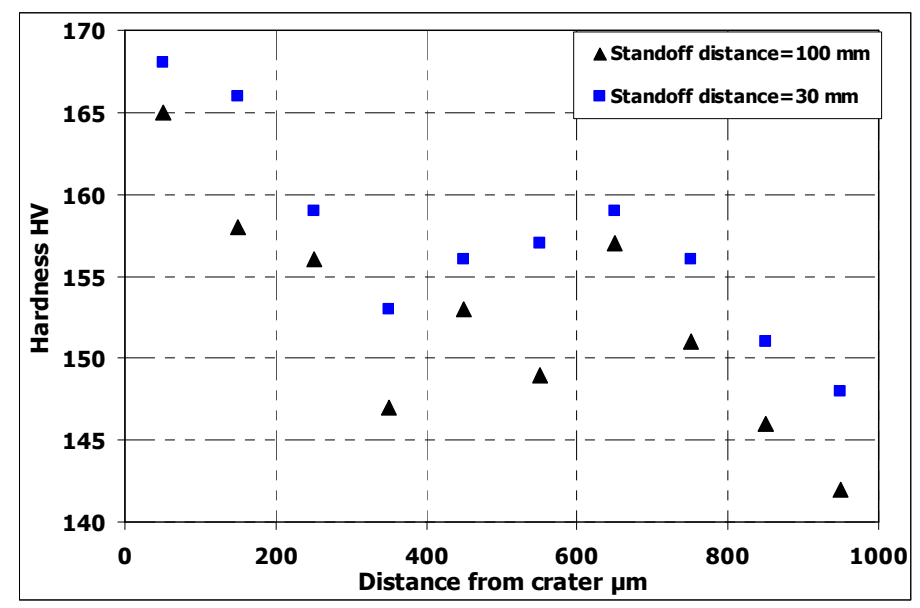

FIGURE 8. Hardness evolution vs. distance from groove

\section{Conclusions}

Surface damage induced by a nitrogen jet under high pressure and low temperature has been observed. The thermo-mechanical shock induced by the nitrogen jet at impact activates extremely diverse damaging modes: cleavage, micro - cavities nucleation and growth, plastic deformation..., depending on the type of impacted material and the operating parameters. The effects of standoff distance in a mild steel were investigated. The rate of material removal increases with standoff distance, then decreases after a certain optimal distance. This result might be explained by the nucleation of liquid (or hypercritic) droplets through turbulent interaction of the jet with the surrounding atmosphere within a certain range of distances from the nozzle. The present results suggest a high capability of the nitrogen jet at surface removal and surface treatment of metallic samples. The jet could be used in applications such as cleaning tanks from chemical deposits, foundry mould, paint and coating removal from various types of surface, decarbonizing and surface hardening. The description of this potential field and the optimization of the performances of the process will be the subject of further study.

\section{Acknowledgements}

The authors received funding under ANR-ADEME grant \#ANR-06-ECOT-Oox, JAZOLTHOP. They gratefully acknowledge the cooperation of their partners in the project: CRITT TJFU, CRITT M2T, LEMTA/LERMAB, TECHNILOR, PROCER and NITROCISION.

\section{References}

1. M.D. Ducos; F. Richard; O. Matile; R. Warnecke; H. Hume; T. Debionne, "New LN2 Cryogenic Process to Strip Parts Thermal Spray Coated". International Thermal Spray Conference \& Exposition 2008: Thermal Spray Crossing Borders (DVS-ASM), 2008. pp. 695-700.

2. P. Dubs; M. Khalij; A. Tazibt; R. Benelmir, "Contribution à la Modélisation Numérique de la Détente d'un Jet d'Azote Sous Haute Pression et Basse Température”. 19ème Congrès Français de Mécanique, Marseille, août 2009. 